\title{
Analysis of the temperature influence on the specific resistance from different fractions of the mixed liquor in a Membrane Bioreactor
}

\author{
J. A. Gil, L. Túa, A. C. Rueda, M. Rodríguez \& D. Prats \\ Water and Environmental Science Institute, University of Alicante, Spain
}

\begin{abstract}
Not many studies have been carried out in order to correlate the temperature influence on the filterability of different mixed liquor fractions, i.e. suspended solids (SS), colloidal matter and soluble organic matter. It is known that temperature has a big impact on the flux in the microfiltration processes, which is directly proportional to temperature. In this paper, a comparative filtration study at four different temperatures $\left(10,20,30,40^{\circ} \mathrm{C}\right)$ is presented. The contribution of the different fractions that comprise the mixed liquor of a Membrane Bioreactor (MBR) is analyzed in sequential steps. In the first step, the resistance offered by the mixed liquor and its dependence on temperature is addressed. In the second step, the mixed liquor is centrifuged in order to remove the suspended solids and analyze the combined resistance offered by both the colloidal matter and the soluble organic matter. In the last step, the colloidal matter of greater than $1 \mu \mathrm{m}$ is removed via filtration, and the effect of dissolved organic matter on filtration is analyzed. Specific oxygen uptake rate (SOUR) and Particle Size Distribution measurements were also carried out in order to complement the data analysis. The mixed liquor used was sampled from a submerged Kubota flat sheet membrane bioreactor situated in the sewage plant of Rincón de León, Alicante, Spain. The variables of this MBR were monitored in order to appreciate any change in parameters that could affect the sludge properties.

Keywords: extracellular polymeric substances (EPS), membrane fouling, resistance, temperature.
\end{abstract}




\section{Introduction}

Membrane Bioreactors (MBRs) have been widely used in wastewater treatment, due to important advantages over traditional technologies [1]. The advantages of the MBR process are the control of solids, a high effluent quality, good retention of all microorganisms and viruses, the maintenance of high biomass concentration and a real compactness [2].

However, a major obstacle in membrane filtration is the rapid decline of permeate flux caused by membrane fouling [2, 3], which leads to frequent membrane cleaning and even replacement, which increase the maintenance and operating costs of MBRs [1].

The principal constituents of the wastewater that are considered to have a greater impact on membrane fouling are mixed liquor suspended solids (MLSS) concentration, sludge particle size distribution, extracellular polymeric substances (EPS) and suspended solids in the supernatant $\left(\mathrm{SS}_{\mathrm{s}}\right)$ [3].

The membrane fouling is explained as a consequence of the interactions between the membrane and the components of mixed liquor which reduces the permeate flux [4]. That occurs because of a series of resistances, which form the basis of the resistance-in-series model [5]. This model has been used due to its facility in quantifying the grade of fouling. The cake resistance $\left(R_{c}\right)$ has been reported as the main contributor to the total resistance $\left(R_{t}\right)$ in MBR processes [5, 6]. The cake layer could be formed by a variety of components such as microorganisms, inorganic and organic compounds like EPS [5].

Temperature affects filtration mainly through the impact on the permeate fluid viscosity. Temperature is also one of the most important environmental factors in biological wastewater treatment [7]. The variations in temperature in a treatment system usually follow the seasonal fluctuations of the local climate.

In many works, the main sludge components that take filterability into account are analyzed. Not much has been studied about the influence of temperature on those. Since both fouling and filterability are determining factors in MBR efficiency and effectiveness, it is of interest to know the effects that variations of temperature can generate, in order to control them, when possible, or simply anticipate the variations in the behaviour of MBR due to temperature changes.

EPS are a complex mixture of polysaccharides, proteins, lipids and humic substances, products that form a highly hydrated gel matrix, and come from the cell lysis, secretion or are already present in the influent [8]. EPS are experimentally identified in two solution forms: bound (or extractable), and soluble EPS (called soluble microbial products, SMP) [9]. Bound EPS occur as a capsule surrounding the bacterial cell wall that enhances flocculation, and the soluble EPS are in solution in the supernatant [10]. In many studies EPS (soluble and extractable) are mostly considered to affect filterability of active sludge, and as the major cause of membrane fouling in $\operatorname{MBR}[10,11]$.

In this study, the first stage of the experimentation consisted of determining the resistance offered both by the mixed liquor and the different fractions. This was carried out at four different temperatures $\left(10,20,30,40^{\circ} \mathrm{C}\right)$ in a dead-end 
filtration. In a second stage, EPS determination in the different sludge fractions and their respective permeates was performed. The effects of the temperature on the resistances by the different fractions of the mixed liquor, taking into account the influence of the EPS concentration at 4 temperatures were analyzed.

\section{Materials and methods}

\subsection{Activated sludge samples}

In order to carry out the experiments, activated sludge from a Kubota flat sheet membrane of a $10 \mathrm{~m}^{3} /$ day flow pilot plant was used. In Table 1 are shown some characteristics of these samples.

Table 1: $\quad$ Mean values of the main characteristics of sludge samples used.

\begin{tabular}{|c|c|c|c|}
\hline Parameter & Exp 1 & Exp 2 & Exp 3 \\
\hline Sludge TS (g/L) & 8.55 & 8.01 & 7.27 \\
\hline Sludge VSS (g/L) & 7.18 & 6.56 & 5.59 \\
\hline Sludge VSS (\%) & 84 & 82 & 77 \\
\hline HRT (hrs) & 21 & 21 & 21 \\
\hline SRT (days) & 185 & 111 & 111 \\
\hline SOUR (mg O 2 /g MLVSS.h) & 0.90 & 1.97 & 3.18 \\
\hline
\end{tabular}

\subsection{Experimental setup and operating conditions}

In order to determine the flux due to each temperature, a dead-end filtration system with an AMICON model 8200 dead-end stirred cell was used (Fig. 1). A polyethylene shell was incorporated around the cell body.

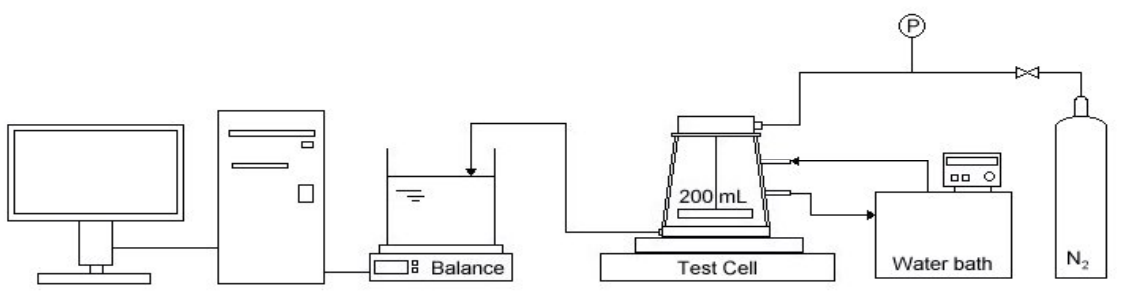

Figure 1: $\quad$ Experimental set-up and test cell.

The experiments were carried out over a period of two days. The first day, the temperatures of baths $\mathrm{N}^{\circ} 1$ and $\mathrm{N}^{\circ} 2$ were fixed at 10 and $20^{\circ} \mathrm{C}$ respectively. At the end of the first day, the temperature of both baths, $\mathrm{N}^{\circ} 1$ and $\mathrm{N}^{\circ} 2$, were respectively changed to 30 and $40^{\circ} \mathrm{C}$. To do the experiments, two samples were taken at the same time. Sample $\mathrm{N}^{\circ} 1$ was used for experiments at 10 and $30^{\circ} \mathrm{C}$, and sample $\mathrm{N}^{\circ} 2$ for experiments at 20 and $40^{\circ} \mathrm{C}$. Both sludge samples were conditioned for 12 hours before the experiments took place, and just after the SOUR was measured. 
Two different types of membranes were used. In order to determine the resistance due to suspended solids and colloidal matter, a $0.4 \mu \mathrm{m}$ hydrophilic chloride polyethylene from Kubota was used. To determine the resistance due to soluble matter, a commercial membrane was used (Whatman, $0.05 \mu \mathrm{m}$ PC).

The supernatant was obtained by centrifuging the temperature conditioned mixed liquor samples for $15 \mathrm{~min}$ at $4000 \mathrm{~g}\left(4^{\circ} \mathrm{C}\right)$. Driving pressure was set to 0.12 bar.

\subsection{Analytical methods}

To determine SOUR, a portable oximeter, WTW model 340i, together with a stirrer, was used. Oxygen uptake rate was determined by monitoring the dissolved oxygen concentration in the mixed liquor. SOUR was then calculated by dividing the oxygen uptake rate by the mixed liquor volatile solids suspension (MLVSS) concentration of the mixed liquor.

\subsection{Filtration resistance determination}

The filtration flux through a uniform membrane surface in a MBR can be described by the general form of Darcy's law [13].

$$
J=\frac{\Delta P}{\mu R_{t}}=\frac{\Delta P}{\mu\left(R_{s s}+R_{\text {sup }}+R_{m}\right)}
$$

where $\mathrm{J}$ is the permeation flux, $\Delta \mathrm{P}$ is the Transmembrane Pressure (TMP) that is applied, $\mu$ is the viscosity of the permeate, and $R_{t}$ is the total resistance, which is the combination of the three resistances, $R_{s s}$, the resistance due to suspended solids, $R_{\text {sup }}$, the resistance due to the supernatant and $R_{m}$, the intrinsic membrane resistance. $R_{\text {sup }}$ is the sum of $R_{\text {col }}$, the resistance that takes into account the colloidal matter and $\mathrm{R}_{\text {sol }}$, which takes into account the soluble matter. $\mathrm{R}_{\mathrm{m}}$ was obtained from experiments with distilled water. Three different filtration tests were carried out as laid out in Fig. 2. The first one was the mixed liquor filtration. $\mathrm{R}_{\mathrm{t}}$ was obtained from this filtration. The second one was filtration of the supernatant coming from the centrifuge. $R_{\text {sup }}$ was obtained in this case. The last filtration used the permeate from the mixed liquor filtration. $R_{\text {sol }}$ was obtained in this last filtration. The two first filtrations used a $0.4 \mu \mathrm{m}$ Kubota membrane, whereas the last filtration used a Whatman $0.05 \mu \mathrm{m}$ membrane.

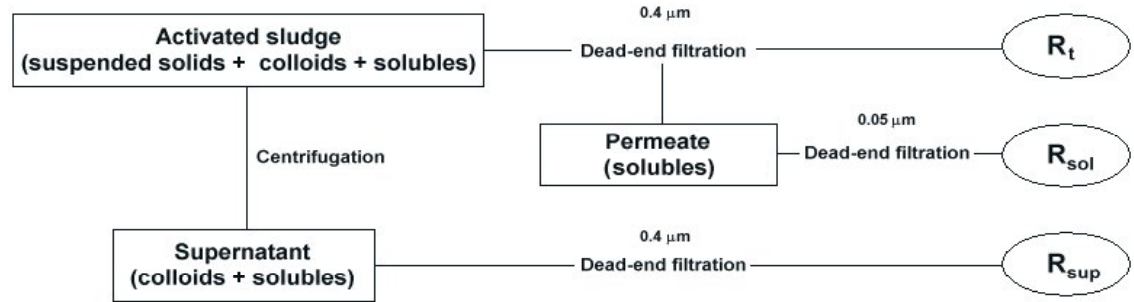

Figure 2: $\quad$ Filtration procedures. 


\section{Results and discussion}

\subsection{SOUR and particle size distribution discussion}

Table 1 shows the different values for suspended solids and SOUR for each experiment. The concentration of suspended solids was kept constant between 7 and $9 \mathrm{~g} / \mathrm{L}$ via wastage between exp. 1 and 2 . The suspended solid concentration drops from 8.55 in the first experiment, to $8.01 \mathrm{~g} / \mathrm{L}$ in the second experiment due to wastage. We noticed a low value of $7.27 \mathrm{~g} / \mathrm{L}$ in the third experiment. This is consistent with the SOUR values since they rise from 0.90 in the first experiment to $3.18 \mathrm{mg} \mathrm{O}_{2} / \mathrm{g}$ MLVSS.h. in the third experiment. As we expected, the extraction of mixed liquor from the reactor increases the microbiological activity.

Floc size ranges from 2.1 to $223.4 \mu \mathrm{m}$ having the maximum percentage value at $5.6 \%$ with a particle diameter of $21.7 \mu \mathrm{m}$. It has been reported that deflocculation is supported by anaerobic conditions and low temperatures [12]. Therefore, a reduction of the particle size with decreasing temperature was expected. Instead, no influence of the temperature on the size of the flocs was found. This could be due to the conditions in our reactor: low dissolved oxygen concentration, close to anoxic conditions, shear stress produced by the aeration and an excess of filamentous bacteria that leads to small size flocs.

\subsection{Resistance of mixed liquor and different fractions at four temperatures}

The resistance of mixed liquor was the first to be analyzed. Previous studies carried out by other researchers show that the increasing resistances at low temperature can be explained by four phenomena occurring in the system: (1) the sludge is more viscous at a low temperature (rather than permeate viscosity), reducing the shear stress generated by coarse bubble aeration and particle deposition on the membrane could be intensified; (2) intensified deflocculation tends to occur at a low temperature, reducing biomass floc size and releasing EPS to the solution, (3) particle back-transport velocity, calculated with the Brownian diffusion coefficient (linearly related to temperature), is less at a low temperature, and (4) biodegradation of chemical oxygen demand (COD) was also reduced at a decreased temperature, resulting in a higher concentration of solute and particle COD in the reactor [13, 14]. According to the arguments of Le-Clech et al. [13], the anticipated behaviour is that observed in experiment 3.

No relation between different concentrations of SS and resistance was obtained in any of the three experiments. These results agree with those obtained by Rosenberger and Kraume [10], who found non impact of SS, on the filterability. Contrary to these results Meng et al. [3] found that MLSS concentration had an exponential relationship with membrane fouling.

Fig. 3a shows a different trend in the three experiments. An increase of resistance with temperature can be observed for experiment 1 , while no trend was observed for experiment 2. Experiment 3 shows a decrease of resistance with temperature. 
In fig. $3 b$ can be seen an increase of resistance with temperature in all the experiments for the supernatant fraction, contrary to what Le-Clech et al. [13] obtained.

Fig. 3c shows the variation of resistance during filtration of the mixed liquor permeate through a $0.05 \mu \mathrm{m}$ membrane. It can be seen that there is not an important variation of the resistance as the temperature increased in exp. 1. A slight increase of the resistance was noted in experiment 2 at $30^{\circ} \mathrm{C}$. In experiment 3 the resistance increased with the temperature, especially at $40^{\circ} \mathrm{C}$.

(a)

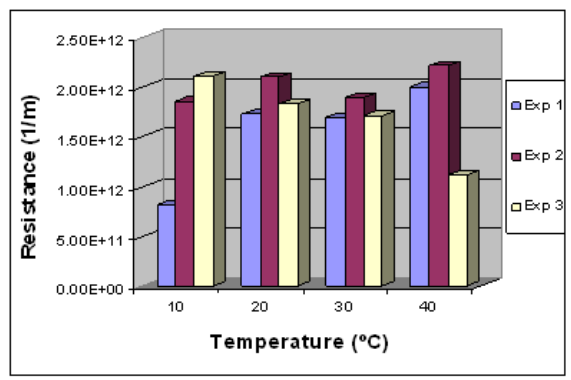

(b)

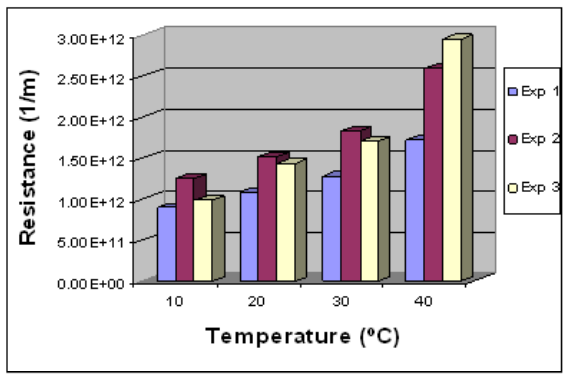

(c)

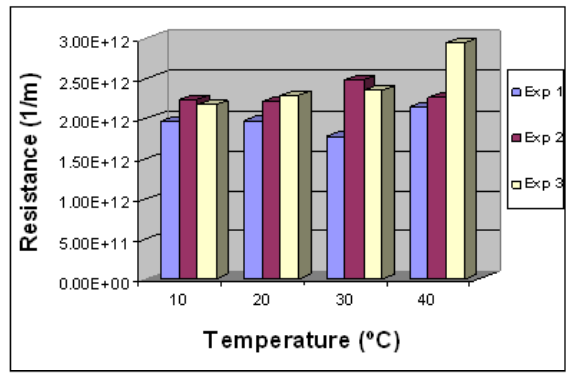

Figure 3: Resistance at different temperatures of: a) mixed liquor, b) supernatant, c) permeate of mixed liquor with $0.05 \mu \mathrm{m}$ membrane.

\subsection{EPS from mixed liquor and fractions at the four temperatures}

In Fig. 4a it can be seen that similar concentrations of EPS in mixed liquor permeated, were obtained for the 3 experiments for temperatures between 10 and $30^{\circ} \mathrm{C}$. At $40^{\circ} \mathrm{C}$ the EPS concentration showed a strong increase.

The influence of temperature and EPS concentration on the mixed liquor filtration may be compared by looking at figs $4 \mathrm{a}$ and $4 \mathrm{~b}$. A decrease in resistance is expected when the temperature increases [13]. This behaviour has been observed in exp 3. On the other hand, in exp. 1 and 2 the resistance increases with temperature.

This behaviour could be explained as follows. Temperature increases or decreases have two opposite effects on mixed liquor filtration. On the one hand, 
a temperature increase favours the filtration of the mixed liquor by the effect of different factors mentioned above, that influences the resistance of the mixed liquor and the characteristics of the membrane. On the other hand, it favours the formation/release of smaller SMP fractions, which is not desirable for the filtration [15]. These opposite effects are counteracted to a certain extent, which is not always the same. Depending on the sludge characteristics and the environmental conditions, one will be more determining than the other.

(a)

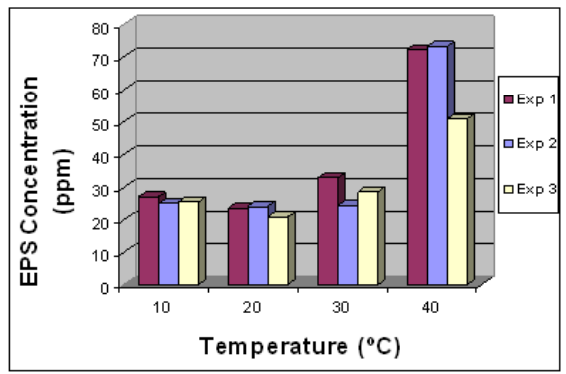

(c)

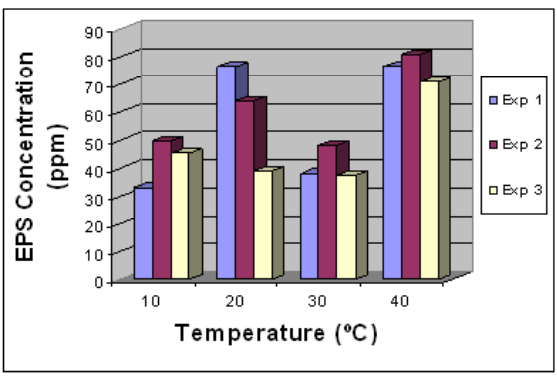

(b)

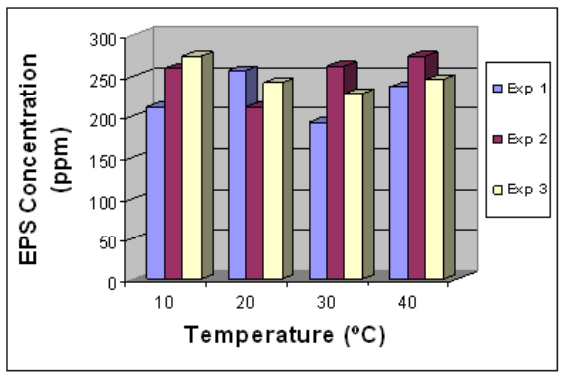

(d)

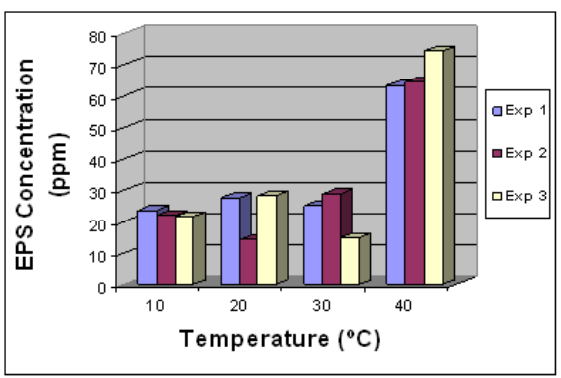

Figure 4: Concentration of EPS at different temperatures in: a) permeate of mixed liquor, b) bound and soluble EPS in the mixed liquor, c) supernatant, d) mixed liquor permeate obtained with the $0.05 \mu \mathrm{m}$ membrane.

Fig. 4b shows the sum of the concentration of soluble and bound EPS, for the mixed liquor in experiment 3 . The contribution of soluble EPS was smaller than $5 \%$. Temperature drops cause an increase in sludge SMP concentration, which is reversible when temperature is increased [15]. In our experiments, this tendency was not observed.

Fig. 4c shows there is no significant variation in the EPS concentration for the supernatant with the temperature, in the range from 10 to $30^{\circ} \mathrm{C}$. In the case of 40 ${ }^{\circ} \mathrm{C}$ the concentration increases considerably. A direct relation between the resistance at $40^{\circ} \mathrm{C}$ and the greater concentration of EPS at this temperature is observed in experiment 3 . 
Fig. 4d shows that the EPS concentrations in the permeate of mixed liquor with the membrane of $0.05 \mu \mathrm{m}$ are similar in the range of temperatures from 10 to $30^{\circ} \mathrm{C}$, which is between 20 and $30 \mathrm{ppm}$ in the three experiments. However, at $40^{\circ} \mathrm{C}$ takes place an increase of around $100 \%$ in the concentration of EPS for the three experiments. This suggests that EPS could be responsible for the creation of a significant barrier to permeate flow [13]. This agrees with fig 3b, since the resistance of the supernatant, that is to say, soluble EPS, reaches the maximum value at $40^{\circ} \mathrm{C}$

\subsection{EPS concentration before and after filtration}

Fig. 5 shows the retention percentage of EPS in the different mixed liquor fractions. The rejection percentage of total EPS and soluble EPS of the mixed liquor fractions are represented separately. The elimination rate for total EPS was around $98 \%$, this percentage of rejection being similar for the range from 10 to $30^{\circ} \mathrm{C}$. At $40^{\circ} \mathrm{C}$ the percentage was around $95 \%$. The soluble EPS rejection percentage obtained was lower since the EPS are dissolved in the liquid and pass through the membrane easily. The higher the temperature is, the lower the retention percentage. A decrease in rejection percentage can be seen from 65.72 at $20^{\circ} \mathrm{C}$ to $7.43 \%$ at $40^{\circ} \mathrm{C}$. The reason may be that increasing the temperature causes a diminution of viscosity [13], that contributes to better filterability and then to less soluble EPS rejection in the membrane [15].

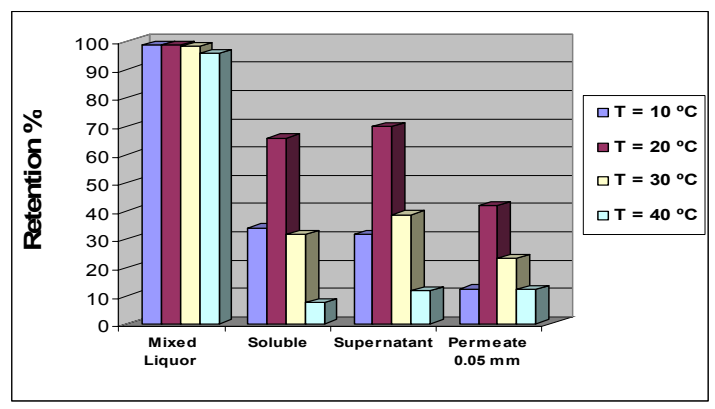

Figure 5: Rejection percentage of EPS in the different mixed liquor fractions.

In the separate fractions, a similar descending tendency for all the fractions is observed upwards from $20^{\circ} \mathrm{C}$ to $40^{\circ} \mathrm{C}$. As the temperature increases, the percentage of rejected EPS is smaller. At $10^{\circ} \mathrm{C}$ unexpected behaviour is observed: the EPS retention is less than at $20^{\circ} \mathrm{C}$.

The explanation could be that at low temperatures, no selective layer on the membrane is formed [15], which allows the SMP to pass easily through the membrane. Comparing the same samples, huge variations in the EPS rejection at 10 and $30^{\circ} \mathrm{C}$ are not observed. However, from 20 to $40^{\circ} \mathrm{C}$ is observed a considerable diminution in the EPS rejection. Fig. 5 shows that the percentage of 
EPS rejected in each one of the filtrations exhibit the same behaviour at the four temperatures, since only the soluble EPS pass through the membrane. Similar amounts of EPS have been observed before and after the filtration with the 0.05 $\mu \mathrm{m}$ membrane at the different temperatures, although the pore size of this membrane is smaller than the Kubota membrane. The reason for this effect could be that the effective pore size of the Kubota membrane is smaller than $0.4 \mu \mathrm{m}$, which leads to low rejection percentages since in the feed the proportion of small particles is greater.

\section{Conclusions}

No influence of temperature on particle size was found, contrary to what many authors report since it was expected that decreasing the temperature would decrease the size of the flocs too. This is probably due to both the small size of the flocs, and the temperate conditioned period probably was not enough.

The lowest rejection percentage was obtained with the $0.05 \mu \mathrm{m}$ membrane for all the temperatures analyzed. The explanation could be because the effective pore size of the $0.4 \mu \mathrm{m}$ membrane decreases, rejecting more soluble matter than was expected.

The behaviour of the separate fractions with the temperature is different from all of them together.

In the case of soluble EPS an increase in the concentration at $40^{\circ} \mathrm{C}$ is observed for all the fractions. Two possible combined effects are present. There exists a critical temperature between 30 and $40^{\circ} \mathrm{C}$ that increases the formation/release of EPS to the liquid phase, and higher temperatures provoke an expansion of the pore size. Because of this, a direct relation between the variation of the temperature with the EPS and the resistance does not exist.

EPS could be responsible for the creation of a significant barrier to permeate flow since the resistance of the supernatant reaches the maximum value at $40^{\circ} \mathrm{C}$, just when the EPS concentration was the highest.

Regarding percentage of rejection, a similar descending tendency in all the fractions is observed. The higher the temperature is, the lower the rejection. This phenomenon is attributed to pore size expansion, and diminution of the viscosity. At $10^{\circ} \mathrm{C}$ unexpected behaviour is observed, the EPS retention is less than at 20 ${ }^{\circ} \mathrm{C}$. This could be because at low temperatures, no selective layer on the membrane is formed, which allows the SMP to pass easily through the membrane.

\section{Acknowledgements}

This study was financially supported by the Foundation Gran Mariscal de Ayacucho (assigned to the Venezuelan Ministry of Superior Education), by the Spanish Ministry of Education and Science and by the Consolider Project CSD 2006-00044. 


\section{References}

[1] Shui-li, Y. \& Fang-bo, Z., Effects of components in activated sludge liquor on membrane fouling in a submerged membrane bioreactor. Journal of Environmental Sciences, 18, pp. 897-902, 2006.

[2] Hernández, M. \& Van Kamm, R., Role and variations of supernatant compounds in submerged membrane bioreactor fouling. Desalination, 179, pp. 95-107, 2005.

[3] Meng, F. \& Zhang, H., Identification of activated sludge properties affecting membrane fouling in submerged membrane bioreactors. Separation and Purification Technologies, 51, pp. 95-103, 2006.

[4] Bouhabila, E. \& Ben Aïm, R., Microfiltration of activated sludge using submerged membrane with air bubbling (application to wastewater treatment). Desalination, 118, pp. 315-322, 1998.

[5] Lee, J. \& Ahn, W., Comparison of the filtration characteristics between attached and suspended growth microorganisms in submerged membrane bioreactor. Water Research, 35, pp. 2435-2445, 2001.

[6] Chang, I. \& Lee, C., Membrane filtration characteristics in membranecoupled activated sludge system - the effect of physiological states of activated sludge on membrane fouling. Desalination, 120, pp. 221-233, 1998.

[7] Chiemchaisri, C. \& Yamamoto, K., Performance of membrane separation bioreactor at various temperatures for domestic wastewater treatment. Journal of Membrane Science, 87, pp. 221-233, 1998.

[8] Reid, E. \& Xingrong, L., Sludge characteristics and membrane fouling in full-scale submerged membrane bioreactors. Desalination, 219, pp. 240 249, 2008.

[9] Ye, Y. \& Le Clech, P. Evolution of fouling during crossflow filtration of model EPS solutions. Journal of membrane science, 264 pp. 190-199, 2005.

[10] Rosenberg, S. \& Kraume, M., Filterability of activated sludge in membrane bioreactors. Desalination, 146, pp. 373-379, 2002.

[11] Liang, S. \& Liu, C., Soluble microbial products in membrane bioreactor operation: Behaviors, characteristics, and fouling potential. Water Research, 41, pp. 95-101, 2007.

[12] Wilén, B. \& Keiding, K., Anaerobic deflocculation and aerobic reflocculation of activated sludge. Water Research, 34, pp. 3933-3942, 2000.

[13] Le-Clech, P. \& Chen, V., Fouling in membrane bioreactors used in wastewater treatment. Journal of Membrane Science, 284, pp. 17-53, 2006.

[14] Jiang, T. \& Kennedy, M., Optimising the operation of a MBR pilot plant by quantitative analysis of the membrane fouling mechanism. Water Science and Technology, 51, pp. 19-25, 2005.

[15] Drews, A. \& Mante, J., Impact of ambient conditions on SMP elimination and rejection in MBRs. Water Research, 41, pp. 3850-3858, 2007. 